\title{
The Social Life of Methods: Devices
}

Special Issue, Journal of Cultural Economy, 2013, Vol. 6, Issue 4

John Law and Evelyn Ruppert, co-editors

\section{Introduction}

First there was the earthquake and then came the tsunami. Hours passed and stories about the Fukushima nuclear plant started: no power; no cooling; overheating; hydrogen explosions and fires; off-site radiation spikes; an evacuation zone. So, here's the question, how far do devices extend? How large or small can they be? Is a nuclear reactor a device? Or a water pump? And how about the radiation monitors catching those spikes? Or the International Nuclear and Radiological Event Scale? (Fukushima started at level 4, and like Chernobyl now ranks at 7). Is this a device as well?

Here's where we start. Devices don't have to be pieces of kit. They don't have to be big - or small - technologies. Rather, they are material and social. The dictionary suggests that we might think of them as patterned teleological arrangements. The Concise Oxford Dictionary mentions heraldic designs and mottos, but its primary definition talks of 'plan, scheme, trick; contrivance, invention, thing adapted for a purpose or designed for a particular function'. So the Fukushima nuclear plant is a teleological arrangement. But so, too, is the International Nuclear and Radiological Event Scale. Or, if we want to think 'social' or 'economic', then the 2011 UK census, the Eurobarometer survey, the first-past-the-post electoral system, the sociological interview, the historians' witness seminar, the collateralised debt obligation, and a royal wedding, all of these are devices; all are more or less patterned teleological arrangements.

Perhaps, then, almost everything of human interest is a device? A newspaper. An app. An identity card, and the state apparatus of surveillance that goes with it. A supermarket's logistical track-and-trace system. The supermarket itself, the shop. The Lord Mayor's Dinner. The British Museum. The Annual Meeting of the British Sociological Association. There's an argument for saying that the world is substantially structured by devices. But to think about this it is useful to first reflect on the key terms here, teleology and arrangement.

\section{Teleology}

As the dictionary reminds us, teleology leads to purpose and to functionality. Devices $d o$ things. But what do they do? Fukushima has been generating electricity, local employment, and fission products for decades, but now it has done other things too. It has emitted radiation, polluted its surroundings, and is having unpredictable effects on the future of nuclear power. But the same logic works for 'social' devices as well. In the UK censuses have been enumerating populations since 1801. But as they count, censuses are doing other things too (Ruppert 2007). They may be creating national identities and national exclusions. They may be helping to build nation-states. They may be generating controversies: with the rise of the digitisation of government records are they really necessary any longer? And (another 'social' device) focus groups have been used by marketers to explore attitudes to products. That is what they 
have been doing routinely since the Second World War. But quite differently and more recently they have been used by critical social scientists to lay bare rhetorical positions and social tensions on matters of contestation - indeed including nuclear power (Waterton and Wynne 1999).

That's the first lesson we want to take away. If devices are patterned teleological arrangements, then they do things. Press on this thought a little, and it becomes tempting to suggest that devices assemble and arrange the world in specific social and material patterns. References might include: Fukushima, where what was being assembled and distributed changed dramatically in March 2011; the census, which turns self-elicited identifications and categories into populations with rates and regularities; the London Congestion charge zone, which regulates and configures patterns of traffic and travel decisions; and the first-past-the-post electoral system, which organises the political and geographical distribution of parliamentary seats, and in the UK usually secures a majority in the House of Commons for a single party. We may imagine, then, that devices like these are social operators; that they all do social work; and that (we've already said this) each of them is doing this in patterned ways that are multiple and diverse.

But there is an obvious corollary. What devices are doing isn't necessarily written on the package. And this is often what the stuff of political and social contestation-not to mention critical social science - is about. It airs what hasn't been written on the package, or it adds its own health warnings. Does the first-past-the-post system help to keep the Conservative party in power in a nation that has a 'natural' radical or at least liberal majority? Yes, said the critics, at least until the hung parliament of 2010. Did collateralised debt obligations help banks to securitise themselves with AAA investments? This is what was written on the package. Only after the 2007-2008 crash did it become clear that local security might lead to global instability. Is nuclear power a safe carbon-free source of electricity? No, say the critics (and they've been saying this since before the Three Mile Island incident in 1979 (Perrow 1999)). Did the question 'what is your religion?' in the 2011 UK Census encourage a positive response that will result in a misleading measure of religious affiliation? Yes, say the lobbyists.

This suggests that any social analysis of devices will be marked by a degree of critical suspicion. Of course there is no harm in reading what's on the package to start with. 'Security cameras reduce theft'. No doubt they do in many circumstances. But then critical social science will go on to look at the small print. 'Security cameras move theft around to places without such cameras.' Or 'security cameras erode privacy'. And it will seek to add to the small print. 'Security cameras erode civil liberties too.' And finally it will argue that what seemed to be small print isn't small print at all: that (for instance) the erosion of civil liberties should be shouted from the rooftops. In short, like all good social science, the social analysis of devices will go looking for agendas that aren't obvious that are nonetheless embedded in their practices. It will go looking for what we might think of as 'collateral realities' (Law 2011) - distributive effects that are being done incidentally and along the way.

And then, as a part of this, it will ask about effects that aren't intentional. For the teleologies of the patterned arrangements we are calling devices may be - indeed very often are-implicit. In ways that interestingly overlap, R.K. Merton talked of the importance of what he called 'latent functions' (unrecognised and unintended social 
consequences (Merton 1957)), while Michel Foucault became preoccupied with implicit strategies, pointing to forms of ordering such as normalisation (Foucault 1979). The latter, he observed, are not the product of centralised deliberation. Instead they spread themselves through and pattern the fabric of the social to operate as a microphysics of power. The well-worn but none the less crucial lesson is that devices and their teleologies do not depend primarily upon strategic subjects. As a generation of feminist and race theory has taught us, the devices of gendering and racialising (if that is what we call them) are all the more powerful for being inexplicit, naturalised, embedded, and endlessly reproduced in the strategically ordered networks of the social (on racial inscription, see M'Charek (2010)). Here, then, the onus is on the analyst. Perhaps there are arrangements that aren't interestingly teleological for critical social science, but if we can't see implicit effects when we start looking at practices then we would suggest that this constitutes a failure in our critical faculties.

\section{Arrangements}

So much for the teleology; but what of the patterned arrangements part of our definition of the device?

There is one way in which the point we need to make is banal. Everything that holds together more than briefly can be understood as a patterned arrangement. The Fukushima nuclear plant is an arrangement that combines pieces of material technology with a range of different forms of expertise, and legislative, economic, and political relations; and natural relations too (for instance radiation). We may think of it as a web that has been arranged (and now disturbed). Coming closer to home, Mike Savage explores the working of the UK's Government Social Survey in the 1950s and the 1960s (Savage 2010). This made use of the (then unusual) technique of sampling and anonymous interviewing to represent the views of particular groups in the population. It was a technique popular with a rising technocratic middle class, which thereby distinguished itself from upper-class gentlemanly intellectuals. And it was used in the 1960s by a modernising government to frame (for instance) a more egalitarian educational policy. Again this counts as a patterned arrangement. It was an arrangement of material elements (including clipboards, calculators, and statistical tables), forms of expertise, and professional and political relations. First off, then, the point is banal, but we make it because we want to press two further points.

First, the patterned arrangements that constitute devices are materially heterogeneous. Devices may and often do include pieces of kit. More generally, patterned arrangements include materials that may but do not need to be high-tech (clipboards and pencils are just as material as nuclear reactors, radiation monitors or computers). But they are heterogeneous because they (usually) include people too (technicians, evacuees, electricity users, members of the technocratic middle class, interviewees). We might add that they typically include texts, inscriptions, representations or symbols too (sample statistics, temperature readings, and graphs revealing radiation spikes). But if devices are materially heterogeneous arrangements, then this suggests that it is important to find ways of tracing the patterning of relations as these pass through — and order - different kinds of materials, human, social and otherwise. It calls for thinking about how devices are active, alive and lively. It becomes important to understand that how they establish relations, how they play out, and who and what they mobilise are to a large extent indeterminate and contingent. That is not to say that the ways they are initially configured, strategically ordered, and organised are 
inconsequential, but it may be that they are only provisional. (Think, for instance, of the sheer heterogeneity of census practices). And this in turn suggests that it might be wise to avoid a narrow definition of 'the social'. Contra Durkheim, it might be better not to think of 'the social' as a separate realm, but instead to imagine it as patterns of association that come in a variety of material forms (Latour 2001).

Second, we want to argue that there is no reason to suppose that devices - that patterned teleological relations - are internally consistent and coherent. We've already seen that they have multiple effects: that they $d o$ a range of different things. We've also, and similarly, argued that they embed or are shaped by a range of different strategies or agendas, and that as they are played out can gather together other devices or enrol different elements and purposes not 'originally' envisaged. All this tells us that devices multi-task, that they embed more or less uncertain (and often implicit) compromises, and that if they appear to be coherent then this is a contingent achievement. Always subject to centrifugal forces, they are potentially fragile (Fukushima; the NHS National Patient Record system; the financial system). This means that if we look inside and turn up the critical magnification we are likely to discover that in practice they are more or less messy patchworks or assemblages rather than perfectly crafted working arrangements. It follows that any claims of perfection by their authors need to be treated with a pinch of salt. They need to be understood as accounts of devices as they were conceived rather than practised. It also, and interestingly, tells us that since non-coherence is a chronic condition what might otherwise be denounced as 'mess' is not necessarily undesirable, a suggestion that in turn carries its own political-cum-analytical lesson (Law 2004). This is why tinkering may be a better model for thinking about how devices work in practice, rather than measuring or trying to understand them in terms of the extent to which they approximate a logic of perfect design (Mol 2008). We're saying, then, to put it differently, that it is better to think of devices as rough and ready assemblages, rather than as well-oiled systems or networks, social or otherwise.

\section{Boundaries}

How far, then, do devices extend? Do we want to say that Fukushima includes all the agendas about civil nuclear power, for and against? Do we want to argue that sample surveys include all the concerns of those who have built and contributed to the apparatuses of sampling statistics? To what extent do we want to include the interests of the banking system - or sub-prime mortgage-seekers - within the device of the collateralised debt obligation? How far do we want to load events such as royal weddings with agendas, national, monarchical, religious, hierarchical, political, military and patriarchal? (e.g., see Tett's (2011) anthropological analysis of the royal wedding). Are there any boundaries to devices once we start to think of these as patterned teleological arrangements? And if so, then how would we set those boundaries?

These are questions that are partially, but only partially, empirical. Looking to see, for instance, how collateralised debt obligations work will lead us relatively easily to discover specific relational patterns -for instance, to do with the repackaging of debt by banks to reduce exposure to, and therefore the cost of financing, what would otherwise be low quality and high risk lending. Clearly, then, in the first instance the empirical clearly needs to be respected, and looking to see what is written on the package is not a bad place to start if we want to do this. But then looking to see what 
others - including especially sceptics — are saying isn't a bad follow-up move for those aspiring to a critical social science. So, for instance, those who have explored the technical default calculations of derivatives such as collateralised debt obligations have discovered that under certain circumstances these predict total default. In this way we start to learn about other plausible teleological patterns embedded in the arrangements of the social. Then, and still in the business of rewriting the small print - or perhaps of blazoning it —we have critical traditions in social science that lead us to look for the operation of systematic but concealed or implicit strategic agendas. So, and still sticking with the financial crisis of 2007 and 2008, an analysis informed by the concerns of political economy suggests that while each transaction in the financial system was clever, these were not only chained together in ways that were dumb (and therefore catastrophic), but that the inquiries into banking regulation blinded themselves to the larger consequences and risks of such arrangements by excluding dissenting voices (CRESC 2009).

One therefore looks, and in some measure one discovers, the patterns that one is searching for. And this tells us in turn that the boundaries of patterned teleological arrangements are flexible. It tells us that where we set the boundaries is an analytical and political matter. It tells that that where we set the boundaries of devices depends on our own questions, and our own agendas. It also tells us that whatever the stories that we tell, whatever it is that we seek to inscribe on the package, these will only ever be partial. There can be no exhaustive analysis of devices. There is always more to be told, more and different, about the work that they do, and about what and how they assemble, distribute and operate upon, the social. So how do we decide where we want to set our boundaries?

Clearly there can be no single answer to this question. It will precisely depend on our own concerns and agendas. And of course those concerns and agendas are often related to the analytic framings that we take up, such as actor-network-theory (ANT), Foucauldian dispositifs and apparatuses, Deleuzian assemblages, or Bourdieusian fields. While each of these also face questions about arrangements and boundaries, they open up kinds of worlds to us that other analytic methods may foreclose. But we want to elaborate this point by reflecting briefly on the devices of professional social science: on our interviews, our surveys and our focus groups; on the devices that we use as we seek to understand and represent the social. This is important because everything that we have said about devices in general applies just as much to those of social science. Indeed, we have said this above: social science methods are more or less precarious patterned teleological arrangements. Possessed of a double social life, they are shaped by the social, and in turn they act as social operators to do the social (Law, Savage and Ruppert 2010). But what follows from this?

One answer is that it will not do to treat social research methods as techniques alone. Of course it is right to think of them in part in this way. This is the writing on the package - or perhaps better the small print. If you want to set up a focus group or run a survey it is indeed important to do this properly. But we should not stop there.

Recognising that we can never find exhaustive answers, we should nevertheless also be asking: what is it that our methods are doing? What do they imply? What kinds of worlds are they opening up to us? And what kinds of worlds are they closing off? So, for instance, if we were to ask about the strategies and assumptions embedded in that 
iconic social research tool, the sample survey, we might want to ask about what it sometimes makes explicit but often implies or takes for granted about:

- the character of the social; where the putative response might be that the social is a particular collection of people, such as a population;

- the character of the elements that make up the social; where the response is likely to be that these are people;

- the particular attributes of those people; which probably include linguistic skills, and the assumption that these skills may be mobilised or probed to discover somewhat consistent attitudes that (in turn) relate to their behaviour;

- the character of representation; where the answer would be that it is possible, within certain statistically bound limits of reliability, to assume that a properly chosen sample can stand for an entire population, and that this (as it were 'democratic' version of the social) is 'properly representative'; and

- the character of social science research; where a possible response might be that it is about collecting linguistic responses from individual people about their attitudes, life-conditions, or experiences, that may then be grouped together and classified into separate sub-populations.

Do not misread what we have just written as an attack on the device of the sample survey. Our concern is analytical rather than normative, and a similar list might be generated for any social research method, quantitative or qualitative. But what it does reveal is that like any other research method the sample survey is a device that is shaped by and reproduces a version of the social (Law, Ruppert and Savage 2011). It is a patterned teleological arrangement that makes assumptions about the character of the social as a collectivity, the components of that collectivity, the attributes of those components, and how best these might be researched. This tells us that it isn't naïve, and neither is it neutral. So while it teaches us about the social (for instance, about people's attitudes to matters of the day) it also carries and rediscovers a set of more or less implicit framing assumptions that we earlier characterised as 'collateral realities'. In short, it necessarily rests in and reproduces a set of often implicit strategies.

Such strategies may or may not be important. If we want to know how people are likely to vote in an election - or about their experiences of educational opportunity and social mobility - then we do not necessarily need to concern ourselves too much about them. The device of the sample survey no doubt does its job very well. On the other hand, once we start to think about research methods as devices, it also becomes interesting and important to think about and explore the social work that they are doing. This is because it is not impossible that we might want to do it differently. Such, then, is the importance of the device, in sociology, and elsewhere. It is not simply a matter of critically exposing explicit and implicit strategies, and of being reflexive about the work being done by our devices. It is equally important to attend to how we make normative and political choices, and the ways in which these have consequences for how our disciplines intervene in the social worlds of which they form a part.

\section{The articles}

The articles in this special issue take up many of these questions. 
A good place to start is with Candea for he directly interrogates our definition of a device as a 'patterned teleological arrangement' to think about two possible and interrelated devices. The first is a biological field site, the Kalahari Meerkat Project (KMP), whose main purpose is to collect observational data on meerkat behaviour and ecology in the field instead of the laboratory. The other is his anthropological field site, which only partly overlaps with the KMP. He notes that both are made up of particular patterned arrangements but rather than holding steady, with each visit he discovers that both shift and change (leading him to state 'you never step twice into the same fieldsite'). Through a series of vignettes he complicates what changed: not only were new elements introduced into the KMP but his 'outlook' had also changed and he saw things that hither to fore were not 'obvious' to him such as experimental interventions. He also complicates the boundaries of his field site (and the archetype of a single, neatly bounded ethnographic location) by describing its multisitedness, which extended spatially from the Kalahari to seminars and libraries in Cambridge and temporally from his discontinuous co-presence to the comings and goings of people, animals and things.

Candea then returns to the definition of a device and concludes that both the biological and anthropological field sites are patterned arrangements and their difference is matter of emphasis: the latter has a flexible, open-ended approach to location and the job is to find pattern and arrangement 'out there in the world'; biologists make explicit their research design and painstakingly define the pattern and arrangement of their field site according to their interests. That point brings Candea to the question of teleology: he counterpoises the KMP as a 'single-mindedly purposeful device' against the ethnographer's openness to the unexpected where aims, purposes and interests get partly redirected. So while both field sites can be understood as devices they are quite differently so.

Through his account Candea highlights that how we conceptualise a device interacts with how we come to 'know' it. As Donna Haraway has put it, we are not simply describing or reflecting what a device is, but 'diffracting', that is, interfering with it. If multiple interferences are possible and productive of multiple differences then the question is: what interferences do we choose? In some ways this is a point taken up in the next article where Law and Singleton also engage with a field site and juxtapose two devices in their ethnography of beef cattle farming practices. In some respects their formulation provides another way to think about Candea's question concerning the differences between devices. They explore a purposeful, patterned, teleological and ordered device, the Cattle Tracing System (CTS) of the British Cattle Movement Service (BCMS) and how it exists in relation to a second, that of the 'farming work' of a particular farmer called Michael. For them the question is, how are the colonizing and imperialist ambitions of the CTS resisted by the subordinated practices of Michael?

They start by arguing that it is through a series of repetitive, recurring, materially heterogeneous practices on the farm that the CTS is enacted. But rather than being stable, its repetitions are malleable and variable, which they argue is what the CTS and any device is. They then describe Michael's farming work as a patterned craft of care that is less explicit and pre-formatted and more fluid and unfolding, though like Candea they temper their comparison to note that the CTS also enacts a version of fluidity. The two devices are two versions and styles of 'malleable repetition' that 
they call rituals and refrains for holding things steady (perhaps a useful term for thinking about Candea's changing field sites). Michael's skilled craftwork is locally passed down and learned through daily situated practices while the CTS is transmitted through disciplinary and generalized practices such as universal prescriptions. Rather than drawing a sharp line between the two, Law and Singleton describe the former as permissive and the latter less tolerant of other realities and practices.

What to make of this asymmetry? The CTS dream of control works by disconnecting from that which does not fit (or disciplines it). But, in an interesting twist, they argue that Michael also disconnects: for example, he sets aside the CTS during the hours that he practices his craft. Keeping some things 'outside' (such as the CTS preference for artificial insemination instead of bulls) they suggest constitutes a form of resistance against being 'captured', of creating a breathing space such that quite different practices can co-exist. They conclude by nuancing Stengers' argument that other worlds are possible and observing that many quietly permissive local devices create many more or less different realities alongside colonising ones.

Muniesa, Vikkelsø and Lezaun take us into laboratory-like spaces instead of 'raw' or 'anti-lab' field sites to think about controlled experiments in the post war period as demonstration devices that create 'pure' realities through 'provocative containment'. Perhaps like the purposeful disconnections of the KMP, CTS and farming work, controlled experiments seek to create bounded spaces. But by interrogating 'provoking' and 'containing' in albeit experimental settings the authors open up broader questions about the 'reality making' of devices more generally. Provocative containment is described as performative and intentional: it seeks to 'trigger an effect, to produce, and to do so in a defiant manner' by containing what is inside the space of an experiment, a definition that certainly echoes the teleology of devices we have suggested above. These effects are explored by drawing on examples such as Kurt Lewin's dramatisations of democratic and autocratic politics and Stanley Milgram's psychological experiments in obedience. Through these they identify five traits at work in provocative containments: trauma, distillation, incitement, technology, and expressionism.

While much criticized for being 'artificial' set-ups, the authors argue that experiments powerfully reveal and make explicit how social realities are incited and enacted by devices. They provocatively suggest that it "is the reality of society "out there", the realism of the phenomena purported to exist "in the wild", that warrants skepticism". Lewin's dramatisations, for example, challenged the 'reality of the democracies people claimed existed' by 'realizing' a democratic atmosphere experimentally. In this way they echo Sloterdijk's techniques of making explicit the 'atmospheric conditions' enrolled in knowing something, and suggest that 'to see or to know something means actually to "do it"'. What devices 'do' is enact realities and more explicitly in the controlled experiment.

While not in a laboratory or controlled experiments, the devices explored by Harvey, Reeves and Ruppert also seek to contain, format and stabilise arrangements through specific technologies: the UK's open government platform, Kyrgyzstan's conflict maps, and Peru's national system of public investment bureaucratic protocol. The authors compare how these purposeful teleological arrangements anticipate moral failure and pursue certainty but in the process generate unintended effects and affects. For one, while seeking a technical settlement by establishing boundaries on what is 
included and made explicit in a device (transparency), the devices displace rather than erase what is implicit, and by their very make-up constantly push the boundaries of what is made explicit (which is the tyranny of transparency). Devices, they say, are thus always and already partial, provisional and destabilising.

But to pursue moral certainty their three transparency devices need witnesses and they do so by calling forth and multiplying 'active' publics, which they argue are not the same as, for example, the credentialed elites of Boyle's seventeenth century experiments in pneumatics who were engaged to legitimise 'matters of fact'. The publics of their transparency devices are less reliable, more unstable and variable and thus a source of uncertainty. While seemingly calling forth rational and calculative subjects, their devices are generative of affective and uncertain subjects with a greater awareness of that which is not yet explicit and that which is yet to be revealed.

Formed in anticipation of moral failure and called upon to identify what might happen such as corruption, wrong doing or inter-ethnic conflict, they suggest that 'contemporary transparency devices' are 'potentially generative of hypervigilant, suspicious and doubtful witnessing subjects, neoliberal subjects who must keep a watchful eye over the micro doings of the state.'

At the end of their analysis they introduce an interesting twist. While at first glance the generation of suspicion and anxiety may appear to work against the objective of moral certainty, they suggest that the generation of uncertainty can be understood as integral to the workings and purposes of these authoritative devices. Uncertainty and hypervigilant and doubtful subjects are perhaps effects and affects that affirm the necessity of these governing devices, feed their perpetuation and call for more of the same. In these ways the authors complicate both the presumed purposes of devices but also their ostensible containment and certainty.

Marres and Weltevrede turn to a differently configured and purposeful digital device used in social research-ScraperWiki-used to extract data generated by online platforms such as Google and Twitter. More generally their device opens up questions about the troubling distinction between social life and social research, and between the real-world concerns of social actors and the epistemological ones of social scientists. They do this by making the concerns of the former part of and constitutive of their object. While the data generated by scrapers are typically problematised because they are not generated or formatted by the researcher and introduce 'alien' assumptions, they turn these features into a source of social data. In this way they complicate what is 'inside' and 'outside' digital social research by inviting other agents into their methods rather than attempting to clean or erase their influence. If the anthropologist is open to definitions and formattings of the worlds of his/her subjects then so too are these digital sociologists.

The authors complicate what ScraperWiki 'is' and 'does': rather than simply collecting data, it extracts already ordered and 'structured information'. But, 'metaphorically speaking', it also involves a 'distillation process' that culls 'formatted data from a relatively opaque, under-defined ocean of available online materials' (perhaps not too unlike the encounter with a field site that presents a flood of heterogeneous data that researchers also distil). But it is these very distillations that they suggest can become social data and objects of research and thereby force the question of 'how we establish the difference between researching the medium and researching the social'. That is, re-purposing data or devices designed for 'other' 
purposes (e.g., commercial) is a way to both do social research and to critically understand how research is being socially and technically redistributed in more implicit ways by digital technologies. Thinking of scrapers as devices draws attention to these entanglements between objects and methods and the impossibility of making distinctions between the instruments, methods and objects of digital social research, as has been argued in philosophy and sociology of science and technology. So rather than problems, they turn features such as the uneven temporalities and 'real time' character of some online data into a 'virtue' through what they term 'live social research', which makes productive the formatted, dynamic character of digital networked data.

Finally, in their article on devices in finance, Erturk, Leaver and Williams return us directly to the question of power. Earlier we noted that what it is that devices do is not necessarily written on the package, and we added that if they may be understood as patterned teleological arrangements, then how we draw boundaries around them is an analytical and political matter: that in some measure we discover the patterns that we are looking for. Erturk et al argue that the social studies of finance (SSF) have chosen to frame their analysis of financial devices in a very particular and indeed narrow way by treating these as an expression of the performativity of economic theory. No doubt this has its merits, but also it means that almost everything not written on the package is simply excluded. Thus they argue that devices do not simply-or perhaps even primarily - format. More importantly, they are used in strategic ways by powerful actors. Drawing, like Singleton and Law on the dictionary definition of devices, they observe that the latter are linked to desires and indeed to dark desires. Their argument is thus that financial devices are marshalled, controlled and deployed by those that are powerful with the strategic aim of creating flows of income. The shift these authors make leads them to Deleuze and to the metaphor of the war machine. In this way of thinking devices turn from tools into opportunistic weapons that are being deployed by financial nomads. Indeed actors such as hedge funds precisely fit Deleuze's analysis of the nomad. They are war machines that are unregulated, pivot around star actors, operate by making unexpected and opportunistic strategic or-perhaps better - tactical moves, and exist in an ambivalent relation with states, which they simultaneously serve and raid.

But how has this worked in the context of finance? The authors answer this by briefly sketching conjunctural changes in the conditions of financial possibility (including the deregulation of flows of international capital and the growth of capital in the form of pension funds). Then they describe how this has led to chains of transactions that offer many individual opportunities for profit. But, and as a part of the same nomadic logic, these chains are opportunistically cobbled together, and lack any overall rationale. Neither, as we learned in 2008, are they necessarily stable: there is always the possibility of catastrophic collapse. In short, in finance devices have become weapons within a war machine, and the tactics of actors such as hedge funds are those of opportunistic bricolage. The consequence is that there is no larger structure or rationality. Overall cohesion is of no concern at all to the financial nomads.

In the end, then, these authors are warning us that a focus on devices is all very well, but that the latter need to be placed in context, and that context takes us back to the concerns of a critical social science. This is because, as we have just noted, it unsurprisingly turns out that it is those who are powerful who are best able to 
manipulate a portfolio of tools and turn these into weapons or war. It is those with power that have the capacity to do so tactically and opportunistically. This is the reason why, five years on from the sub-prime crisis, we are in a position where major reforms in finance still elude political grasp, while levels in inequality in developed Western countries are progressively increasing as wages, salaries and the provisions of the welfare state are all being squeezed for those who do not belong to the elite.

To conclude, the papers in this special issue are diverse. But the focus on 'the device' reminds us that methods for knowing and handling the world have their own social life. Indeed, it reminds us that they have a double or even a triple social life. First, they are shaped by the social. We know enough to know that the tools to hand are never innocent. Second, they work to format social relations, for it is indeed clear that they operate in ways that tend to enact particular structures or forms of organisation. But then, and third, they are also used opportunistically by social actors in the systematic pursuit of political, economic and cultural advantage. How these three dynamics intersect with one another is a crucial question. It is crucial substantively, but also counts as a profound theoretical puzzle. This is because it takes us to a set of unresolved questions at the heart of social theory. The issue is how to think well in the space defined by the intersection between the intuitions of: social constructivism; the microphysics of the Foucauldian tradition with its successor projects such as actor network theory; and the critical concern of radical social theory with institutionalised inequalities. If we want to understand how devices work we will need to draw on all three traditions.

\section{Acknowledgments}

We are grateful for the advice and input of the Editors of the Journal of Cultural Economy and our contributors who responded to our initial provocation and through their diverse articles enlarged our thinking on devices and the social life of methods. We wish to also acknowledge our colleagues in and beyond CRESC for extended reading group and workshop reflections on the character of devices. We would particularly like to thank: Michelle Bastian, Francis Dodsworth, Penny Harvey, Hannah Knox, Adrian Mackenzie, Ruth McNally, Andy Miles, Niamh Moore, Madeleine Reeves, Mike Savage, Alban Webb and Karel Williams.

\section{References}

CRESC (2009) An Alternative Report on Banking Reform, CRESC, Manchester.

Foucault, M. (1979) Discipline and Punish: the Birth of the Prison, Penguin, Harmondsworth.

Latour, B. (2001) 'Gabriel Tarde and the End of the Social', in P. Joyce (ed.), The Social in Question. New Bearings in History and the Social Sciences, Routledge, London, pp. 117-132. Also available at http://www.ensmp.fr/ latour/articles/article/082.html.

Law, J. (2004) After Method: Mess in Social Science Research, Routledge, London. Law, J. (2011) 'Collateral Realities', in F. Domínguez Rubio and P. Baert (eds), The Politics of Knowledge, Routledge, London, pp.156-178 
Law, J., E. Ruppert, and M. Savage (2011) 'The Double Social Life of Methods', Working Paper 95, CRESC, Manchester. Also available at http://bit.ly/14Ruh3u.

M'Charek, A. (2010) 'Fragile differences, relational effects: Stories about the materiality of race and sex', European Journal of Women's Studies, vol. 17, no. 4, pp. 307-322.

Merton, R. K. (1957) 'Manifest and Latent Functions', in R. K. Merton (ed.), Social Theory and Social Structure, Free Press, New York, pp. 60-69.

Mol, A. (2008) The Logic of Care: Health and the Problem of Patient Choice, Routledge, London.

Perrow, C. (1999) Normal Accidents: Living with High Risk Technologies, Second Edition, Princeton University Press, Princeton and Chichester.

Ruppert, E. (2007) 'Producing Population', Working Paper 37, CRESC, Manchester. Also available at http://www.cresc.ac.uk/publications/producing-population.

Savage, M. (2010) Identities and Social Change in Britain since 1940: The Politics of Method, Oxford University Press, Oxford.

Tett, G. (2011) 'Subtexts of the Wedding Script', Financial Times, FT Weekend Magazine, 30 April 2011.

Waterton, C. and B. Wynne (1999) 'Can Focus Groups Access Community Views?', in Rosaline Barbour and Jenny Kitzinger (eds), Developing Focus Group Research: Politics, Theory and Practice, Sage, London. 